\title{
Pointed Tip Shape Effect on Aerodynamic Load for NREL Phase VI Wind Turbine Blade
}

\author{
Kyoungsoo Lee, Shrabanti Roy, Ziaul Huque, Raghava Kommalapati, Chao Sui, and Nazia Munir
}

\begin{abstract}
This paper presents the pointed tip effects on the aerodynamic load of NREL Phase VI wind blade rotor. The aerodynamic loads around flow field are evaluated using 3D CFD simulation. The commercial ANSYS Fluent and parameterized 3D cad models of NREL Phase VI are used for the analyses. The simple Spalart-Allmaras turbulence model and 0-degree yaw angle condition are adopted for CFD analysis. The pointed tip shape was made by reducing the original NREL chord length gradually near the tip region. To find out the 3D pointed tip effects on aerodynamic load, the pressure coefficient and integrated drag force and torque about primary axis are calculated. The numerical difference of $\mathrm{Cp}$ on wind blade surface between original and modified pointed tip models is negligible except near tip region, and also shown good agreement with experimental result in low wind speed case, however there is more deviation between the experimental data and CFD for high wind speed case, especially on the blade upper surface. Because the flow is highly unsteady, and the massive separation occurred due to the high angle of attack created by the higher wind speed while the rotational speed of the wind blade is kept constant for all cases.
\end{abstract}

Index Terms-Wind energy, wind blade, CFD, NREL phase VI, pointed tip.

\section{INTRODUCTION}

Wind energy is a popular form of renewable energy due to its low $\mathrm{CO}_{2}$ emissions compared to most conventional thermal power plants, and it reduces the use of conventional fossil fuel and this ultimately helps to reduce the emissions of the gases responsible for the green house effect. The blades of a wind turbine rotor are generally regarded as the most critical component of the wind turbine system. The aerodynamic profiles of wind turbine blades have crucial influence on aerodynamic efficiency of wind turbines.

The pointed tip of blade commonly used in commercial wind turbine system as shown in Fig. 1. Even minor alterations in the shape of the profile like pointed tip blade can greatly alter the power curve and noise level. The aim of this study is to analyze the effects of a pointed tip at NREL Phase VI wind blade [1]-[4] on the overall aerodynamic

Manuscript received February 20, 2015; revised July 23, 2015. This research was supported by the National Science Foundation (NSF) through the Center for Energy and Environmental Sustainability (CEES), a CREST Center (Award No. 1036593).

Kyoungsoo Lee is with the Center for Energy and Environmental Sustainability (CEES), Prairiew View A\&M University, Prairie View, TX, 77446, USA (e-mail: kylee@ pvamu.edu).

Shrabanti Roy, Ziaul Huque, Raghava Kommalapati, Chao Sui, and Nazia Munir are with the Mechanical Engineering Department, CEES, Prairiew View A\&M University, Prairie View, TX, 77446, USA (e-mail: rshrabanti@pvamu.edu, zihuque@pvamu.edu, rrkommalapati@pvamu.edu, csui@pvamu.edu,nmunir@pvamu.edu). performance. To pursue the accuracy and applicability of CFD simulation process in wind blade design field, the NREL Phase VI wind blade shape (Fig. 2) is selected which used S809 airfoil profile for section, in which extensible experimental [1]-[4] and numerical data [5]-[11] were reported by many researchers previously, and compared with CFD results of this study.

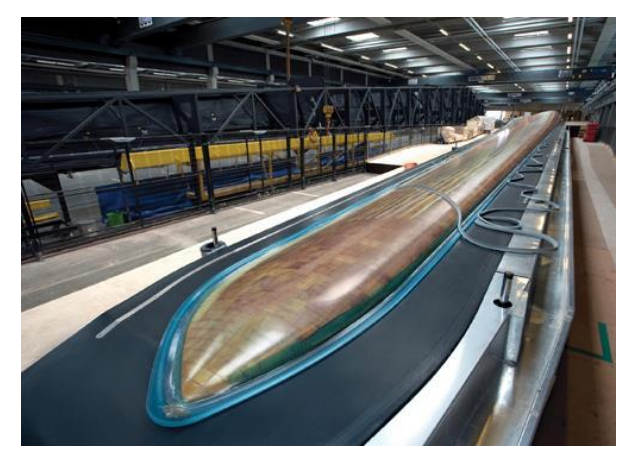

(http://www.compositesworld.com/)

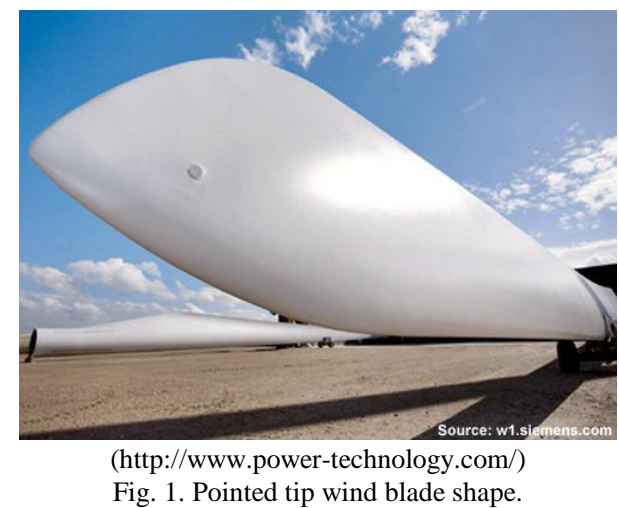

The commercial ANSYS Fluent is used to carry out the CFD simulations of flow over the NREL wind blade. Geometric and mesh modeling are done using ANSYS ICEM modules. The 3D parametric modeling methodology used and enable to make the wind blade in parametric control. The unstructured meshes are adopted for fluid domain grid, the easy to use and perform the analysis is the advantage of it. However, to obtain the high quality meshes in sharp edge and curved surface, it needs more number of meshes than structured. The geometry construction started by importing the S809 airfoil profile coordinates. The bottom-top approach is used to create the $3 \mathrm{D}$ blade geometry using fifteen cross-sections by joining with Non-Uniform Rational B-Spline (NURBS). The flow domain has divided into the ambient and rotational domain to account the rotating motion of wind blade rotor and inlet wind velocity inflow.

The pointed tip was modeled by reducing the chord length near the tip region gradually. To evaluate the pointed tip 
effects on aerodynamic load (Fig. 3), the pressure coefficient and integrated torque about primary axis are calculated and compared with computational results of original NREL wind blade shape and experimental data.



(a) NASA Ames Research Center full scale aerodynamic complex

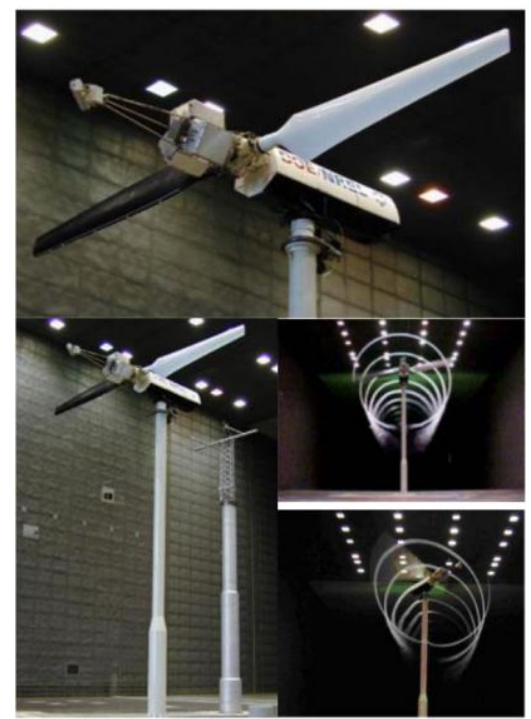

(b) Full scale NREL Phase VI wind turbine blade

Fig. 2. NASA Ames Research Center full scale aerodynamic complex: NREL Phase VI wind turbine blade [3], [4].

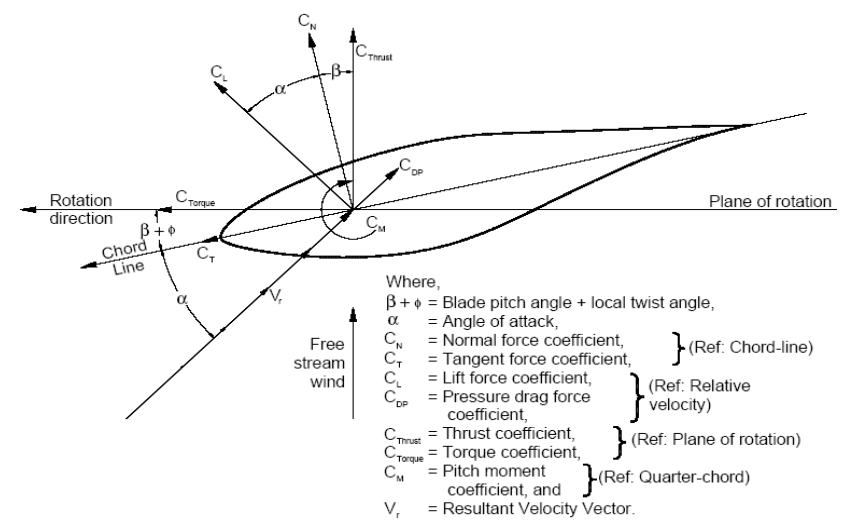

Fig. 3. Aerodynamic force coefficient conventions [3].

\section{POINTED TIP SHAPE OF NREL PHASE VI WIND TURBINE BLADE}

To test the pointed tip effect of wind blade on the aerodynamic load, the wind blade profile of NREL Phase VI wind blade is adopted. There is comprehensive information about the unsteady aerodynamic experiment of it, and its primary objective was to provide information needed to quantify the full scale, 3D aerodynamic behavior of horizontal-axis wind turbines (HAWT). From the field-testing, it has shown that 3-D effects are prevalent in wind turbine field operation, the wind turbines undergo very complex aerodynamic response phenomena when operating in the field environment [3]. It is not considered in wind turbine design codes which are derived from the steady state 2D wind tunnel airfoil test. To provide the needs of accurate $3 \mathrm{D}$ aerodynamic force which is considering the inflow turbulence and shear across the rotor plane, the wind tunnel test was performed by NREL using Phase VI wind blade [3], [4]. From the rigorous experimental wind tunnel test, accurate quantitative aerodynamic and structural measurements on a full scale wind turbine blades were acquired.

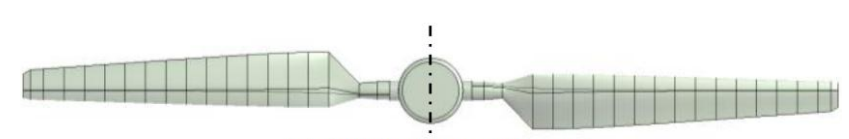

(a) NREL Phase VI wind turbine blade'

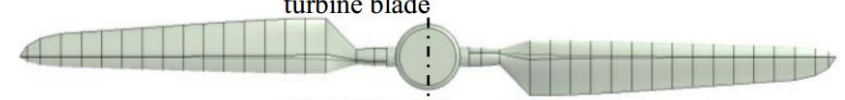

(b) Pointed 'tip of NREL model $>$

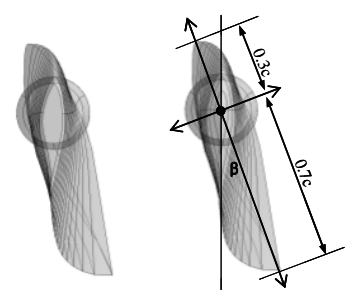

(c) Section of twist angle

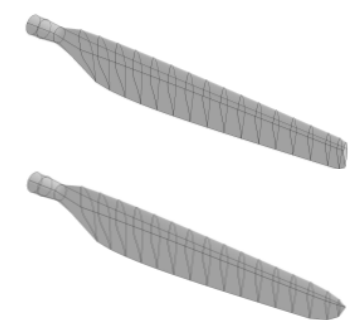

(d) Original and pointed tip of NREL model>

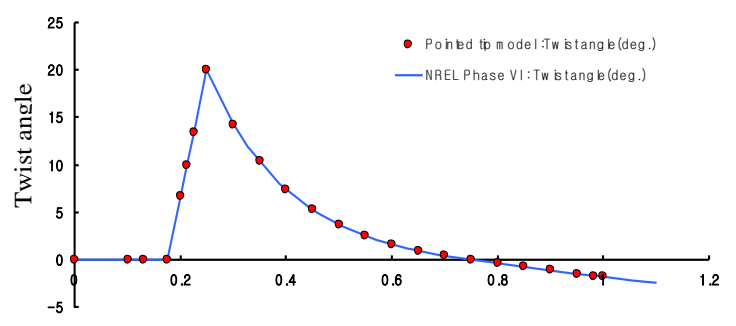

(e) Twist angle distribution along span ratio

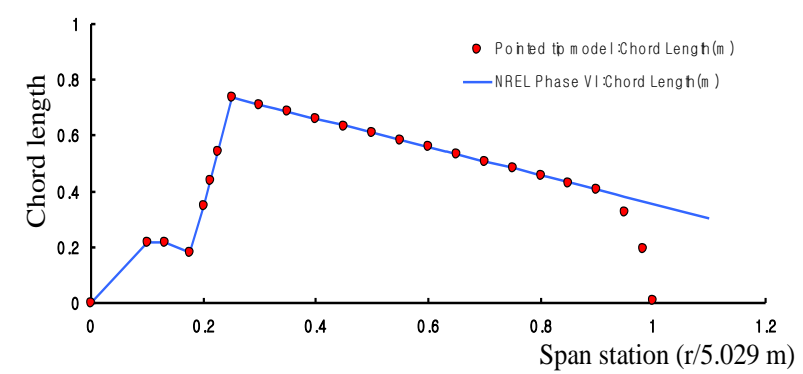

(f) Taper (chord length) distribution along span ratio

Fig. 4. Pointed tip NREL Phase VI wind blade configuration. 
As shown in Fig. 4, the wind turbine blade of NREL Phase VI is based on the S809 airfoil with $10.058 \mathrm{~m}$ diameter rotor, and is both nonlinearly twisted and linearly tapered [3]. The blade chord tapered from $0.737 \mathrm{~m}$ at $0.25 \mathrm{R}$ to $0.356 \mathrm{~m}$ at the tip. Blade section twist decreased from $20.0^{\circ}$ at $0.25 \mathrm{R}$ to $-2.0^{\circ}$ at the tip. Between $0.25 \mathrm{R}$ and the tip, blade cross-section was uniform, corresponding to the $\mathrm{S} 809$ airfoil. The airfoil section at $0.25 \mathrm{R}$ was joined to the pitch shaft section at $0.12 \mathrm{R}$ using linear segments to yield an uninterrupted transition between these two disparate contours. The blade pitched about an axis located 0.30-chord of the leading edge, and centered between the blade upper and lower surfaces at that chord location.

To prepare the pointed tip wind blade model, the original NREL blade are modified to form the pointed tip shape by reducing the original NREL chord length gradually near the tip region. The nonlinear twist angles are identical to the original NREL Phase VI wind blade.

\section{CFD METHODOLOGY}

In this study, the commercial CFD code, ANSYS Fluent was used to evaluate the pointed tip effect on the aerodynamic load of NREL Phase VI wind blade. To minimize the unsteady effect, the cone and yaw angles are set to zero, and the effects of rotor tower and nacelle on the flow field have not been considered because it is upwind stream. Only the upwind configuration has been investigated. The constant wind $(7 \mathrm{~m} / \mathrm{s})$ and rotation speed $(72 \mathrm{rpm})$ are applied in corresponding to the NREL experimental study [3], [4]. The simulations were performed by using steady state turbulence model Spallart-Allamas model. The fluid domain was separated into ambient and rotating domains using the interface boundary. The wind blade is located inside rotating domain with slip wall boundary condition.

The computational ambient domain is $20 \mathrm{~m}-20 \mathrm{~m}-30 \mathrm{~m}$ size hexagonal shape. The inlet and pressure outlet boundaries are placed to make free inflow velocity to the upwind direction. The rotating domain has a cylindrical shape with diameter of $10.4 \mathrm{~m}$ and length of $18 \mathrm{~m}$. The unstructured meshes are prepared using ANSYS ICEM for Fluent. The simulations were performed using both original and pointed tip blade models. The pressure coefficient, $\mathrm{Cp}$ are calculated at span ratio $(r / R)$ of $30.0 \%, 46.7 \%, 63.3 \%, 80.0 \%$ and $95.0 \%$ according to the NREL's report [3], [4] as shown in Fig. 5, and compared with NREL experimental data. Fig. 6 shows the details of computation domains and wind blade shapes.

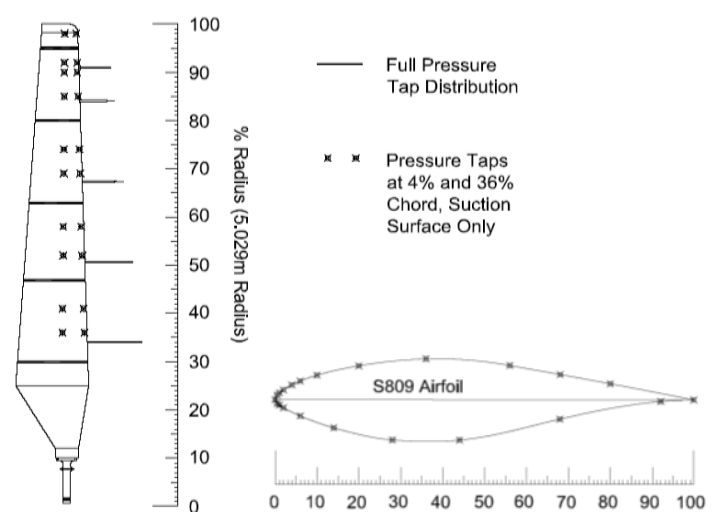

Fig. 5. Surface pressure tap location: NREL Phase VI wind blade [3].
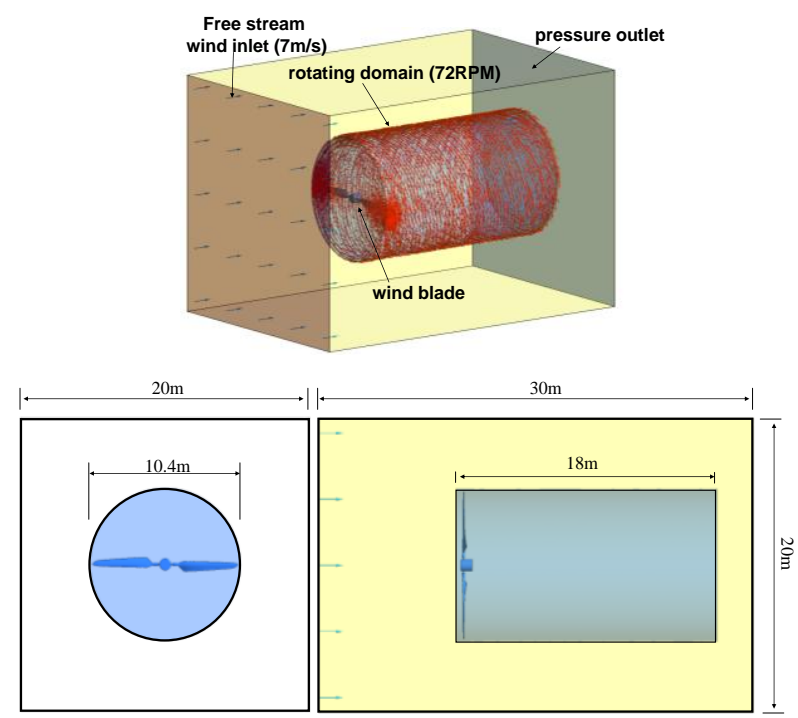

(a) domain definition

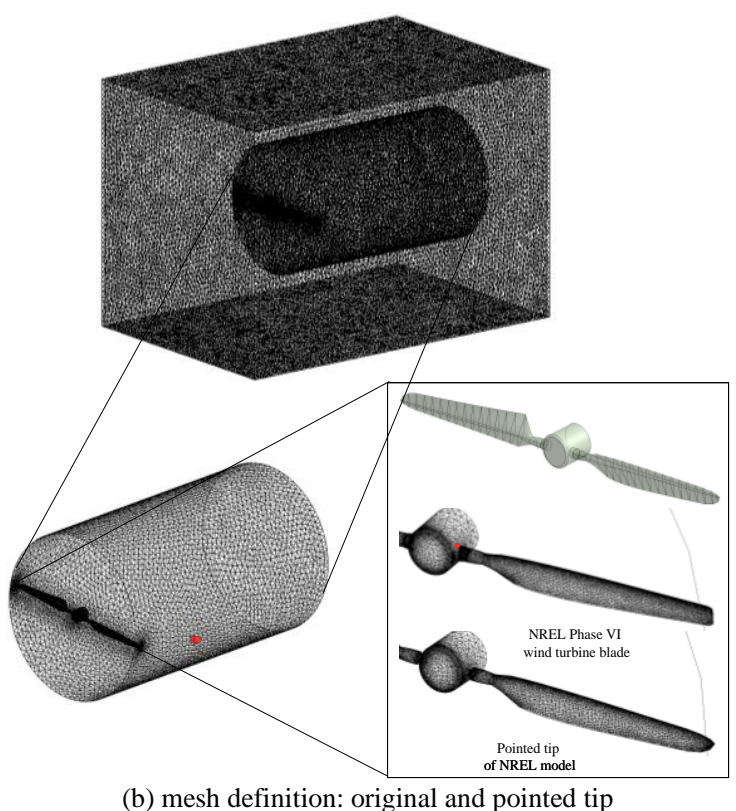

Fig. 6. Domains and unstructured mesh.

\section{CFD RESUlt AND Discussion}

NREL performed wind tunnel test in various wind speed cases $5 \mathrm{~m} / \mathrm{s}$ to $25 \mathrm{~m} / \mathrm{s}$ with constant rotating speed of $72 \mathrm{rpm}$ [3], [4]. From the experimental studies, the real scale wind turbine blade performances were reported for an overall range of operating conditions. In this paper, only the results of $7 \mathrm{~m} / \mathrm{s}$ wind speed case was included. The air pressure coefficients, $\mathrm{Cp}$ are compared with NREL experimental data to verify the simulation.

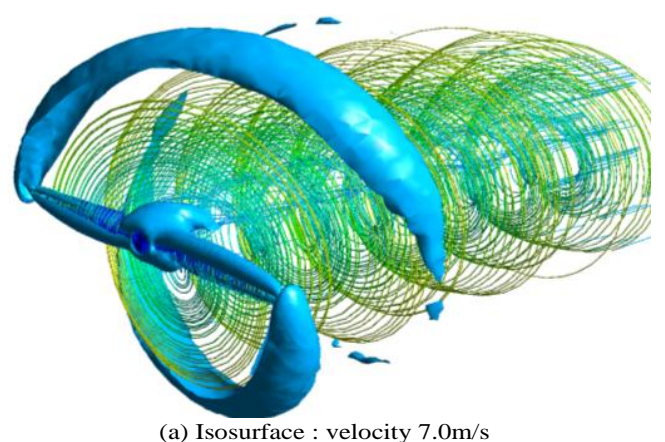

(a) Isosurface : velocity $7.0 \mathrm{~m} / \mathrm{s}$ 




(b) Velocity contour plot : Rotating domain

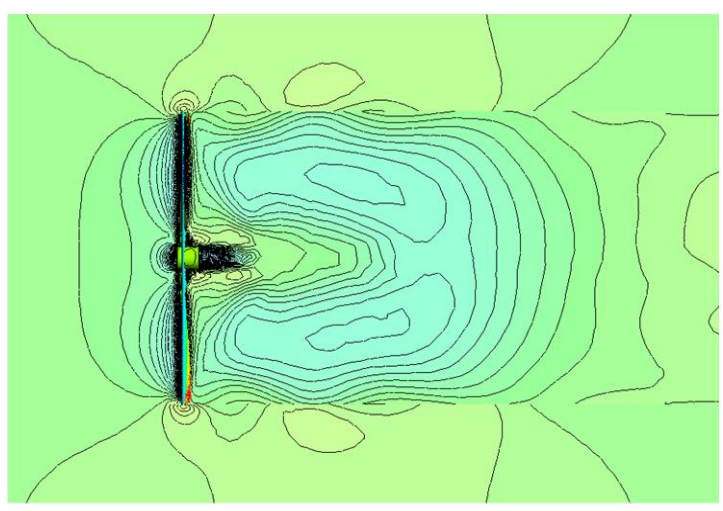

(c) Velocity contour plot: Top view

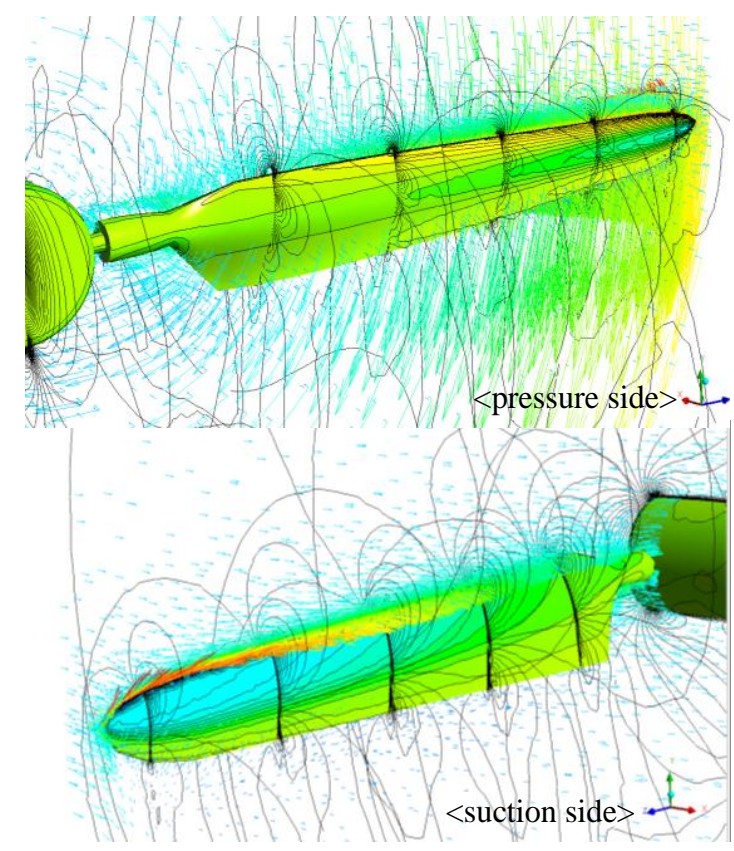

(d) Surface pressure and sectional velocity contour

Fig. 7. CFD results: Velocity contour plots for pointed tip model.

Fig. 7 illustrates various results of iso-surface of scalar velocity value (Fig. 7(a)), sectional velocity contour on rotating domain (upwind and top view, (Fig. 7(b), fig. 7(c))) and wind blade surface pressure and sectional velocity contour plots (Fig. 7(d)).

As shown in Fig. 8, the span-wise pressure distributions are measured to calculate the pressure coefficient from the relative velocity. The relative wind velocity can be calculated by considering the wind speed $(7 \mathrm{~m} / \mathrm{s})$ and radial rotor rotating speed $(\mathrm{r} \omega)$ at different each sections $(r / R 30 \%, 46.7 \%, 63.3 \%$, $80 \%$ and 95\%). From the CFD simulations, the overall performances of pointed tip and original NREL wind blades are shown almost identical. The results of both wind blade models show good agreement with NREL experimental data. As shown in Fig. 5, the numerical difference of $\mathrm{CP}$ on wind blade surface between original and modified pointed tip models are negligible except near tip region at section of $r / R=95.0 \%$. And the surface pressure based integrated drag force and torque about primary axis of pointed tip model are lower than original NREL wind blade because of decreased surface area near the tip, but the differences are negligible.

Ferrer and Munduate [12] proposed the advantages of tip shape for aerodynamic load on blade. The pressure distribution $(\mathrm{Cp})$ of pointed tip model near the tip (at $r / R=95.0 \%$ ) can be higher than non-pointed tip model, but it is minimum or negligible. The reduced section area near the tip may drop the advantage of optimized tip shape in contributing to the power generation (torque). As explained by Sezer-Uzol and Long [7], the flow is attached with low angle of attack due to the low wind speed $(7 \mathrm{~m} / \mathrm{s})$, and make the simulation steady flows near the wind blade, whereas it is massively separated for higher wind speed cases $(25 \mathrm{~m} / \mathrm{s})$. If inflow wind speed is increases, even with constant rotating speed, the angle of attack will increase [6], [7].

The low wind speed of this study made the low angle of attack. As a result, the flow near the blade wall was attached which can avid the unsteady flow effects. Therefore, the steady state simulation with Spalart-Allmaras turbulence model can make the reasonable results which are in good agreement with experimental data. The pointed tip blade shows inferior performance on aerodynamic load than original NREL wind blade, but the pointed tip shape can reduce the structural vibration and the fatigues, can reduce the unsteady turbulence and vortex also.

\section{CONCLUSION}

The pointed tip effects of NREL Phase VI wind blade on the aerodynamic load are presented using 3D CFD simulation for low wind speed case $(7 \mathrm{~m} / \mathrm{s})$ in constant rotor $\mathrm{rpm}$. To preserve the steady state, the unsteady effects are omitted. The low wind speed produced low angle of attack, and the flow was attached avoiding the unsteady flows. The steady state CFD results on pressure distribution, which was evaluated by the means of $\mathrm{Cp}$, of this study using Spalart-Allmaras turbulence model are in good agreement with NREL experimental data. The CFD results of pointed tip model show little difference to the results of original NREL blade shape, and also are in good agreement with NREL experimental data. The decreased value of surface integrated drag force and torque about primary axis are obtained because of the reduced surface area in pointed tip region, but it is negligible compared to total values. Rather it can help to increase the structural stability and reduce the vortex near the tip region. 


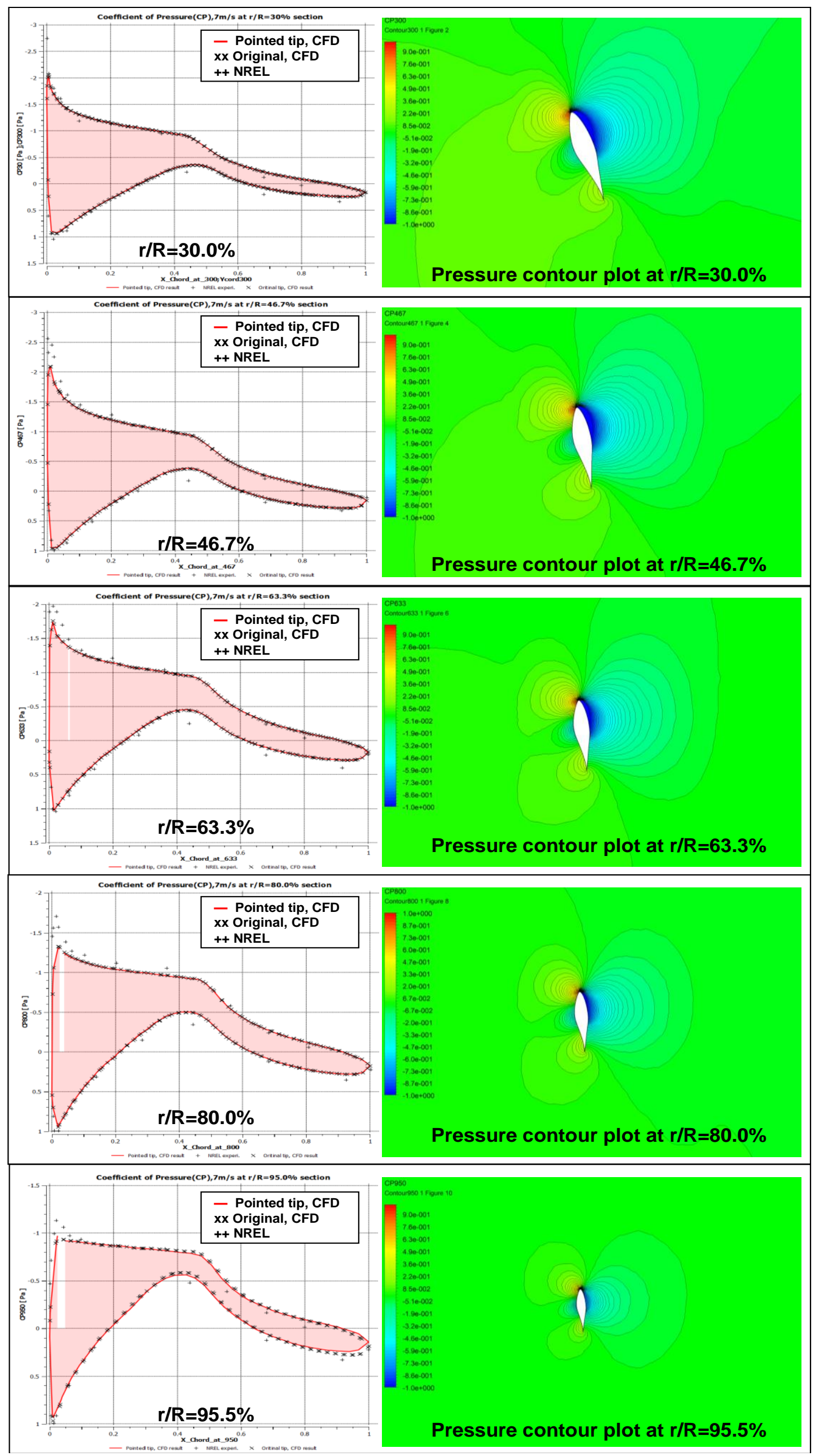

Fig. 8. CFD results: Pressure coefficients (CP). 


\section{REFERENCES}

[1] R. R. Ramsay, M. J. Hoffman, and G. M. Gregorek, "Effects of grit roughness and pitch oscillation on the S809 airfoil," NREL/TP-442-7817, 1995.

[2] D. M. Sommers, "Design and experimental results for the S809 airfoil," NREL/SR-440-6918, 1997.

[3] M. Hand, D. Simms, L. J. Fingersch, D. Jager, S. Larwood, J. Cotrell, and S. Schreck, "Unsteady aerodynamics experiment phase VI: Wind tunnel test configurations and available data campaigns," NREL/TP-500-29955, 2001.

[4] D. Simms et al., "NREL unsteady aerodynamics experiment in the NASA-Ames wind tunnel: A comparison of predictions to measurements," NREL/TP-500-29494, 2001.

[5] E. P. N. Duque, M. D. Burklund, and W. Johnson, "Navier-stokes and comprehensive analysis performance predictions of the NREL phase VI experiment," Journal of Solar Energy Engineering, vol. 125, pp. 457-467, 2003.

[6] C. Tongchitpakdee et al., "Numerical simulation of the aerodynamics of horizontal axis wind turbines under yawed flow conditions," in Proc. AIAA Aerospace Sci. Meeting and Exhibit, 2005, pp. 281-304.

[7] N. Sezer-Uzol and N. L. Long, "3-D time-accurate CFD simulations of wind turbine rotor flow fields," in Proc. 44th AIAA Aerospace Sciences Meeting and Exhibit, 2006, pp. 1-23.

[8] J. O. Mo and Y. H. Lee, "CFD Investigation on the aerodynamic characteristics of a small-sized wind turbine of NREL PHASE VI operating with a stall-regulated method," Journal of Mechanical Science and Technology, vol. 26, no. 1, pp. 81-92, 2012.

[9] Y. Li, K. J. Paik, T. Xing, and P. M. Carrica, "Dynamic overset CFD simulations of wind turbine aerodynamics," Renewable Energy, vol. 37, no. 1, pp. 285-298, 2012.

[10] M. M. Yelmule and E. Anjuri, "CFD predictions of NREL phase VI rotor experiments in NASA/AMES wind tunnel," International Journal of Renewable Energy Research, vol. 3, pp. 250-260, 2013.

[11] R. Lanzafame, S. Mauro, and M. Messina, "Wind turbine CFD modeling using a correlation-based transitional model," Renewable Energy, vol. 52, pp. 31-39. 2013.

[12] E. Ferrer and X. Munduate, "Wind turbine blade tip comparison using CFD," Journal of Physics, 2007.

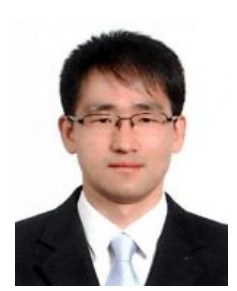

Kyoungsoo Lee received his B.S., M.S., Ph.D. degrees from the Department of Architectural Engineering, Inha University, Incheon, South Korea. $\mathrm{He}$ is working for the CEES, Prairie View A\&M University, Prairie View, Texas, USA as a postdoc. researcher. He was a research professor in the Department of Civil \& Environmental Engineering, KAIST in South Korea. His professional areas are the structural engineering and design, CFD, FSI and impact \& blast simulation. Currently, he is focusing on developing the sound noise simulation for the wind blade. Dr. Lee is the member of AIK, KSSC in South Korea.

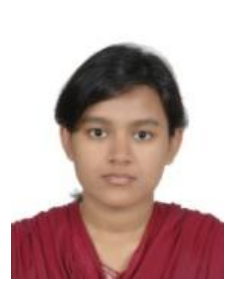

Shrabanti Roy received her B.S. degree in mechanical engineering from Military Institute of Science \& Technology, Bangladesh, 2011. She is currently a master student at Prairie View A \& M University, Texas and also works under the Center for Energy \& Environmental Sustainability (CEES). Her major concentration is on mechanical engineering and interest area is CFD, thermo fluid science and wind energy.

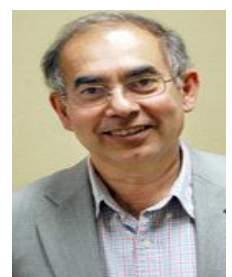

Ziaul Huque received his BS degree in mechanical engineering from Bangladesh University of Engineering and Technology, Bangladesh, MS degree in mechanical engineering from Clemson University, USA and Ph.D. degree in mechanical engineering from Oregon State University, USA. He is currently a professor in the Department of Mechanical Engineering and the director of Computational Fluid Dynamics Institute at Prairie View A\&M University. His current research interests are wind turbine noise reduction, fluid-structure interaction, propulsion, inlet-ejector system of rocket based combined cycle engines, clean coal technology, self-propagating high-temperature synthesis. He received several excellence in teaching and service awards from Roy G. Perry College of Engineering, Lockheed-Martin Tactical Aircraft Systems Teaching Excellence Award, Welliver Summer Faculty Fellowship from Boeing in 2002 and NASA Summer Faculty Fellowship in 2003.

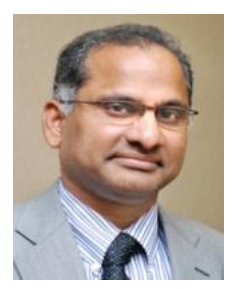

Raghava Kommalapati received his B.Tech degree in civil engineering and M.Tech degree in engineering structures from India. And he received his M.S. and Ph.D. degrees in civil engineering (environmental engineering) form Luisiana State University, Baton rouge, LA, USA in 1994 and 1995 respectively. Dr. Kommalapati is the pricipal investigator and director of the Center for Energy and Environmental Sustainability, a NSF funded center. He is also a professor in the Civil \& Environmental Engineering Department. He served as an Interim Department head of Civil \& Environmental Engineering for 3.5 years between Jan 2010 and Auguest 2013. He is a registered professional engineering (PE) in the State of Texas and a board certified environmental engineer (BCEE). His major field of study is environmental engineering with particular focus on energy and environmental sustainability and air quality. He is the author/editor of on book, and have published more than 35 peer-reviewed journal articles and more than 90 proceedings and presentations at regional, national and international conferences. He is a member of several professional organizations including AEESP, AAEES, ACS, ASCE, ASEE and so on.

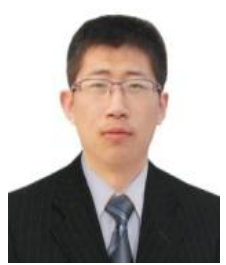

Chao Sui received his BS degree in mechanical engineering from Shan Dong University of Technology, China, 2013. He is currently pursuing a master degree of mechanical engineering at Prairie View A \& M University, Texas, USA. He also works under the Center for Energy and Environmental Sustainability (CEES). Chao Sui's research interests are optimization of wind turbine blade, CFD and thermodynamics.



engineering.
Nazia Binte Munir received her BS degree in mechanical engineering from Military Institute of Science and Technology (MIST), Bangladesh, 2011. She is currently a masters student at Prairie View A\&M University, Texas, USA and also working under Center for Energy and Environmental Sustainability (CEES). Her major concentration is on mechanical engineering and her research interests are CFD, wind energy, thermal 